OPEN ACCESS

Edited by:

Yang Yang,

Northwest University, China

Reviewed by:

Fan Peng,

Fourth Military Medical University,

China

Agnieszka Swiatecka-Urban, University of Pittsburgh, United States

Belinda Jim,

Jacobi Medical Center, United States

*Correspondence:

Yifei Zhong

yifeilily@126.com

John Cijiang He

cijiang.he@mssm.edu

Specialty section

This article was submitted to

Cellular Endocrinology,

a section of the journal

Frontiers in Endocrinology

Received: 03 July 2018 Accepted: 01 October 2018

Published: 17 October 2018

Citation:

Zhong Y, Lee K and He JC (2018) SIRT1 Is a Potential Drug Target for Treatment of Diabetic Kidney Disease.

Front. Endocrinol. 9:624.

doi: 10.3389/fendo.2018.00624

\section{SIRT1 Is a Potential Drug Target for Treatment of Diabetic Kidney Disease}

\author{
Yifei Zhong ${ }^{1 *}$, Kyung Lee ${ }^{2}$ and John Cijiang He ${ }^{2,3 *}$ \\ ${ }^{1}$ Division of Nephrology, Longhua Hospital, Shanghai University of Traditional Chinese Medicine, Shanghai, China, ${ }^{2}$ Division \\ of Nephrology, Department of Medicine, Icahn School of Medicine at Mount Sinai, New York City, NY, United States, ${ }^{3}$ Renal \\ Section, James J. Peters VA Medical Center, Bronx, NY, United States
}

Multiple studies have demonstrated a critical role of Sirtuin-1 (SIRT1) deacetylase in protecting kidney cells from cellular stresses. A protective role of SIRT1 has been reported in both podocytes and renal tubular cells in multiple kidney disease settings, including diabetic kidney disease (DKD). We and others have shown that SIRT1 exerts renoprotective effects in DKD in part through the deacetylation of transcription factors involved in the disease pathogenesis, such as p53, FOXO, RelA/p65NF-кB, STAT3, and PGC1 $\alpha / P P A R \gamma$. Recently we showed that the podocyte-specific overexpression of SIRT1 attenuated proteinuria and kidney injury in an experimental model of DKD, further confirming SIRT1 as a potential target to treat kidney disease. Known agonists of SIRT1 such as resveratrol diminished diabetic kidney injury in several animal models. Similarly, we also showed that puerarin, a Chinese herbal medicine compound, activates SIRT1 to provide renoprotection in mouse models of DKD. However, as these are non-specific SIRT1 agonists, we recently developed a more specific and potent SIRT1 agonist (BF175) that significantly attenuated diabetic kidney injury in type 1 diabetic OVE26 mice. We also previously reported that MS417, a bromodomain inhibitor that disrupts the interaction between the acetyl-residues of NF-kB and bromodomain-containing protein 4 (BRD4) also attenuates DKD. These results suggest that SIRT1 agonists and bromodomain inhibitors could be potential new therapuetic treatments against DKD progression.

Keywords: SIRT1, acetylation, diabetic kidney disease, bromodomain inhibitor, podocytes

\section{INTRODUCTION}

Sirtuin family of nicotinamide adenine dinucleotide $\left(\mathrm{NAD}^{+}\right)$-dependent deacetylases, a homolog of yeast Sir2 (silent mating type information regulation 2), has been shown to play an important role in a variety of cellular functions. The mammalian Sir2 ortholog, Sirtuin-1 (SIRT1) is upregulated by caloric restriction and mediates the longevity effect of calorie restriction by regulation of glucose and lipid metabolism $(1,2)$. At the cellular level, SIRT1 regulates variety of processes including autophagy (3), energetic homeostasis (2), mitochondrial biogenesis (4), and apoptosis (5). A large body of evidence suggests that SIRT1 plays a major role in various kidney diseases by providing protection against cellular stresses associated with kidney injury (6-8). Here, we provide an overview of the role of SIRT1 in kidney cells in the context of diabetic kidney disease (DKD), with a focus on its role on the regulation of transcription factor activation. The review also discusses the potential new therapies by targeting SIRT1 pathway for DKD. 


\section{ROLE OF SIRT1 IN REGULATION OF TRANSCRIPTION FACTOR ACETYLATION}

Recent evidence suggests that transcription factor activation is regulated not only by protein phosphorylation, but also by acetylation. SIRT1 exerts biological effects not only through deacetylation of histones, but also deacetylation of various transcription factors that include p53, FOXO, RelA/p65, STAT3, PGC1 $\alpha$, and PPAR- $\gamma$ (9), thereby leading to transcription repression. SIRT1 regulates p53 activity through deacetylation (10-13) and promotes cell survival through suppression of p53dependent apoptosis in response to DNA damage and oxidative stress (5). SIRT1 was also shown to regulate the activities of FOXO family of transcription factors through deacetylation (14). Deacetylation of FOXO3 by SIRT1 enhances its ability to induce cell cycle arrest and resistance to oxidative stress, while inhibiting its ability to induce cell death $(14,15)$. We also showed that SIRT1 inhibits podocyte apoptosis through deacetylation of FOXO4 $(16,17)$. Several studies suggest that the transcriptional activity of signal transducer and activator of transcription 3 (STAT3) is also negatively regulated by SIRT1 (18-20). SIRT1 was found to cause the deacetylation and inactivation of STAT3 during caloric restriction (21). SIRT1 also exerts anti-inflammatory effects through the inhibition of NF- $\kappa \mathrm{B}$ pathway. It was shown that the duration of nuclear NF- $\mathrm{KB}$ action is highly regulated by reversible acetylation $(22,23)$, and that SIRT1 inhibits the NF- $\kappa B$ signaling pathway through deacetylation of p65 (24). In addition, SIRT1 modulates cellular response to hypoxia via deacetylation of hypoxia-induced factor $1 \alpha$ (HIF-1 $\alpha)(25-27)$. All these highlight an important transcription modulatory function by SIRT1 activity.

\section{SIRT1 PROVIDES RENOPROTECTION AGAINST DKD}

Diabetic kidney disease (DKD) is the leading cause of chronic kidney disease and end-stage renal failure in the US (28). Even with optimal therapy, the incidence of DKD remains high, as none of the currently available therapy can reverse or completely forestall the progression of DKD. Therefore, development of more effective treatment for DKD is urgently required. The important role of SIRT1 in DKD has been demonstrated by number of studies (Table 1). We have previous shown that SIRT1 expression is significantly reduced in human kidney with DKD and that its reduction is more pronounced in the glomerular compartment than in the tubular compartment (17). An association between single nucleotide polymorphisms within SIRT1 gene and DKD was observed in Japanese subjects with type 2 diabetes (40). However, the exact mechanism of regulation of SIRT1 expression in DKD remains unclear. On the cellular level, SIRT1 has been shown to regulate autophagy $(41,42)$ and oxidative stress response in the diabetic kidneys (35). Resveratrol was shown to attenuate DKD through activation of AMPK/SIRT1 pathway $(29,31)$ and by modulating angiogenesis $(43)$. Studies have demonstrated a clear role of SIRT1 in renal tubular cells in the setting of acute kidney injury $(6,44)$. In diabetic kidneys, it was shown that reduced proximal renal tubular SIRT1 expression contributes to albuminuria by upregulation of the tight junction protein Claudin-1 in podocytes (32). Interestingly, reduction in Sirt 1 expression in tubular cells induced hypomethylation of the claudin-1 gene in podocytes to promote its expression, while overexpression of Sirt 1 in tubular cells induced hypermethylation of claudin-1 and downregulated expression in podocytes, indicating an important cross-talk between the two cell types and epigenetic regulation of Claudin-1 expression by SIRT1. Work from our laboratory also demonstrated a critical role of SIRT1 in podocyte injury in DKD. We showed that either knockdown or knockout of Sirt1 specifically in podocytes aggravated DKD injury in type 2 diabetic $d b / d b$ mice (33) and in STZ-induced diabetic mice (34). Importantly, our recent study demonstrated that the podocyte-specific overexpression of SIRT1 was sufficient to significantly attenuate podocyte injury and to impede DKD progression in typel diabetic OVE26 mice. Together, these studies clearly demonstrate a protective role of SIRT1 against DKD in experimental models of both type 1 and type 2 diabetes.

\section{RENOPROTECTIVE MECHANISMS OF SIRT1 IN DKD}

As the cellular and molecular mechanisms of SIRT1 has been recently reviewed $(42,45,46)$, as well as the role and mechanism of other sirtuins in kidney disease (47), this review is focused primarily on its modulation of transcription factor through deacetylation in the setting of DKD.

\section{Effects of SIRT1 in Inflammation in Diabetic Kidneys Through NF- $\mathrm{kB}$ and STAT3 Deacetylation}

Many studies suggest that SIRT1 regulates activity of several transcription factors that regulate kidney cell homeostasis and are involved in pathogenesis of DKD through deacetylation. Systems biology analysis of microarray data suggests that JAKSTAT and NF-KB are key inflammatory pathways activated in diabetic kidneys $(48,49)$. Recently, we showed that the acetylation of STAT3 and RelA/p65 is increased in kidneys from diabetic patients and mouse models (33). More importantly, we demonstrated that the podocyte-specific knockout of Sirt1 in $d b / d b$ mice led to higher levels of p65 and STAT3 acetylation and resulted in greater degree of proteinuria and kidney injury than in control $d b / d b$ mice, implicating SIRT1 as a key inhibitor of the NF-KB- and STAT3-induced inflammatory responses in DKD (33). In addition, we found that expression of the key proinflammatory factors mediated by NF-kB and Stat 3 were also increased in the kidney of Sirt1 knockout $d b / d b$ mice, further confirming a key role of Sirt1 in regulation of inflammation in the diabetic kidney.

\section{Effects of SIRT1 in Cell Death in Diabetic Kidneys Through p53 and FOXO4 Deacetylation}

Several lines of evidence indicate that p53 mediates apoptosis of both podocytes and tubular epithelial cells in DKD (50-52). SIRT1 has been shown to promote cell survival by suppressing p53-dependent apoptosis in response to DNA damage and 
TABLE 1 | Summary of the in vivo studies of SIRT1 in DKD.

\begin{tabular}{|c|c|c|c|c|}
\hline Approaches & Animal models & Tissue/Cell types & Mechanisms regulated & References \\
\hline Dietary restriction & Diabetic Wistar fatty (fa/fa) rats & Whole kidney & Inflammatory; autophagy & (29) \\
\hline Resveratrol & $\mathrm{db} / \mathrm{db}$ mice & Whole kidney & Oxidative stress & (30) \\
\hline Resveratrol & $\mathrm{db} / \mathrm{db}$ mice & Whole kidney & AMPK/PGC1a; Oxidative stress & (31) \\
\hline nicotinamide mononucleotide & STZ-induced diabetic and db/db mice & Tubule/podocyte crosstalk & Epigenetics, Claudin-1 & $(32)$ \\
\hline Sirt1 knockout & $\mathrm{Db} / \mathrm{db}$ mice & Podocytes & Inflammation; apoptosis & (33) \\
\hline \multicolumn{5}{|l|}{ Pyridoxamine } \\
\hline Sirt1 knockdown & STZ-induced diabetic mice & Podocytes & Mitochondria; senescence & (34) \\
\hline hnRNP F & $\mathrm{db} / \mathrm{db}$ mice & Tubular cells & Oxidative stress & (35) \\
\hline Glycyrrhizic Acid & $\mathrm{db} / \mathrm{db}$ mice & Whole kidney & AMPK/PGC-1a & (36) \\
\hline Puerarin & STZ-induced diabetic eNOS-null mice & Podocytes & Oxidative stress; inflammation & (37) \\
\hline Tangshen formula & STZ-induced diabetic rats & Whole kidney & NF-kB/inflammation & (38) \\
\hline Sirt1 overexpression; agonists & OVE26 mice & Podocytes & Mitochondrial function; apoptosis & (39) \\
\hline
\end{tabular}

oxidative stress (5). The interplay of SIRT1-p53 pathway also controls cellular senescence (53-55). We reported previously that advanced glycation endproducts (AGEs) induce podocyte apoptosis through FOXO4-mediated Bim expression and that acetylation of FOXO4 is critical for mediating this effect (17). Overexpression of SIRT1 inhibited AGE-induced FOXO4 acetylation and podocyte apoptosis.

\section{Effects of SIRT1 in Mitochondrial Dysfunction and Fibrosis in Diabetic Kidneys Through of PGC-1 $\alpha$ and Smad3 Deacetylation}

SIRT1 has also been shown to regulate PGC-1 $\alpha$ activity and to play an important role for maintenance of mitochondrial function in podocytes (56). The PGC-1 $\alpha$ in regulation of mitochondrial function has been well described for neurodegenerative disorders (57). Both mitochondrial injury and cellular senescence are key pathological processes mediating kidney injury (58-60). Consistent with this, we have shown recently SIRT1 deficiency in podocytes aggravates agingrelated kidney disease through enhanced cells senescence and mitochondrial dysfunction (61). Although the effects of SIRT1 on Smad3 acetylation remain to be determined, resveratrol was shown to affect acetylation but not phosphorylation of Smad3 to inhibit TGF- $\beta 1$-induced up-regulation of collagen IV and fibronectin mRNA levels in vitro and renal fibrosis in the model of unilateral ureteral obstruction (UUO) in vivo (62). Therefore, it is plausible that increased SIRT1 activity may also attenuate renal fibrosis in DKD. Taken together, these studies suggest that SIRT1, as a negative regulator of inflammation, cellular senescence and mitochondrial dysfunction, is a key repressor of DKD pathogenesis.

\section{SIRT1 IS A POTENTIAL DRUG TARGET FOR TREATMENT OF DKD}

Given that SIRT1 is a key mediator in thwarting the progression of DKD and other kidney diseases, development of therapeutic

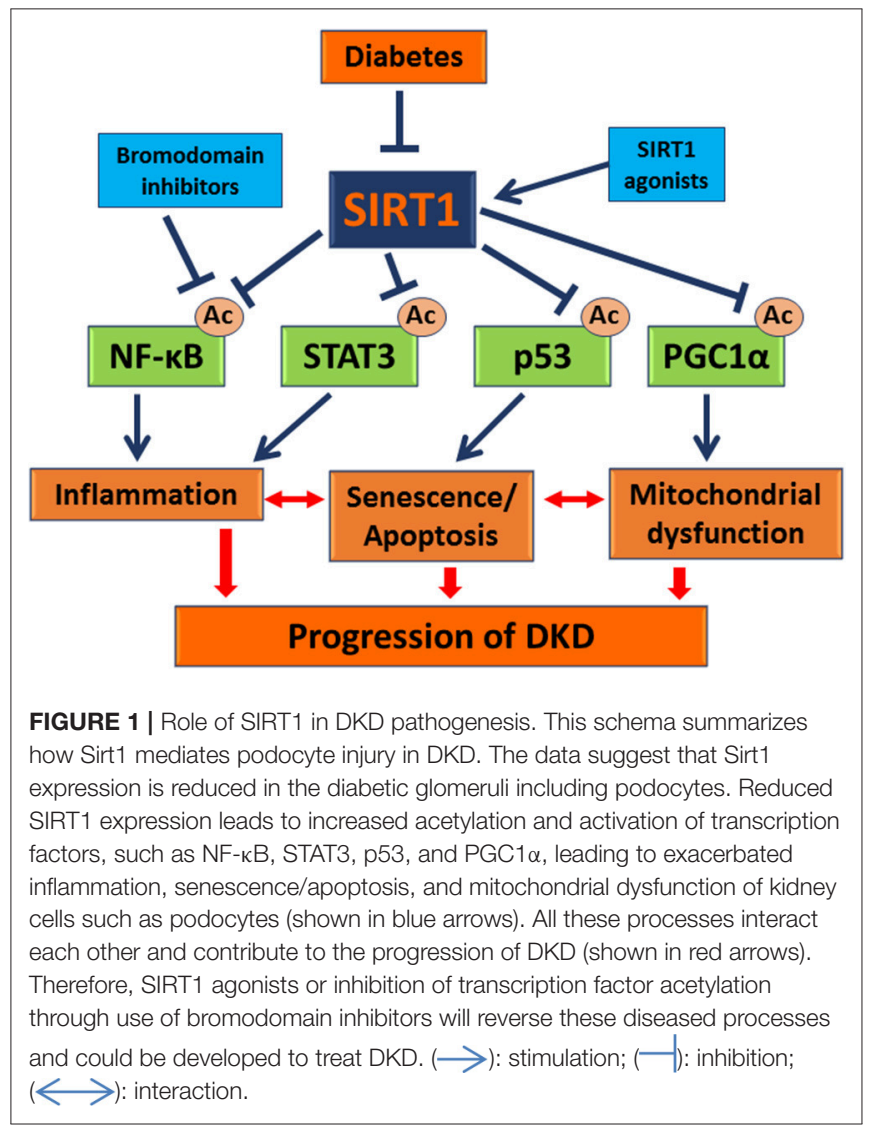

strategies to specifically restore SIRT1 activity is warranted. In support of this, we recently demonstrated that increased SIRT1 expression in podocytes attenuated albuminuria and glomerular injury in OVE26 diabetic mice (39). As SIRT1 expression is reduced in diseased kidneys, identifying the molecular basis of its suppression in diabetic kidneys and to interfere in this process may be an avenue of therapeutic approach. We previously showed that increased advanced glycation endproducts (AGEs) 
in in the diabetic milieu contribute to reduced SIRT1 expression in podocytes (17). Inhibition of AGE formation by pyridoxamine in vivo restored SIRT1 expression the glomeruli of $d b / d b$ mice and attenuated podocyte injury and progression of DKD (17). Similar observations of SIRT1 reduction by AGEs were made in mesangial cells in vitro (63).

Another approach would be to stimulate SIRT1 activity through SIRT1 agonists. Resveratrol is a well-known SIRT1 agonist that has shown to improve DKD in several animal models $(30,31)$. However, recent reports indicate that resveratrol may not be a SIRT1-specific (64), nor are other purported SIRT1 agonists, such as SRT1720, SRT2183, and SRT1460 (65). We also showed that puerarin, an extract from a Chinese herbal medicine, attenuates diabetic kidney injury through activation of SIRT1 and suppression of NOX4 expression in podocytes in experimental diabetic mouse model (62). Other herbal medicines or compounds have also been reported to improve DKD through activation of SIRT1 $(36,38)$. Metformin is reported to improve podocyte function by activating SIRT1 (66). However, SIRT1independent effects on podocytes or in DKD by non-specific SIRT1 agonists or metformin cannot be ruled out. Recently, we developed a new potent and selective SIRT1 agonist, BF175 (39). In cultured podocytes BF175 increased SIRT1-mediated activation of PGC1- $\alpha$ and protected against high glucosemediated mitochondrial injury. In vivo, administration of BF175 for 6 weeks in type 1 diabetic OVE26 mice resulted in a marked reduction in albuminuria and in glomerular injury in a manner similar to podocyte-specific SIRT1 overexpression. BT175 treatment also attenuated diabetes-induced podocyte loss and reduced oxidative stress in glomeruli of OVE26 mice. Therefore, BT175 and its analogs could be developed as novel therapeutic strategy to treat DKD. However, these approaches of targeting SIRT1 are not without limitations. As discussed above, the specificity of the SIRT1 agonists remains a concern. Given the heterogeneity of SIRT1 function, the ever expanding list of its substrates, and the different effects of deacetylation on its target protein functions, it's possible that the beneficial effects of SIRT1 are mixed with potentially pernicious side effects.

As SIRT1 exerts its renoprotective effects through deacetylation of key transcription factors (TFs) involved in $\mathrm{DKD}$, another therapeutic approach may be to directly regulate the transcription factor acetylation through bromodomain inhibitors (BrDi). Acetylated lysines of the key TFs involved in
DKD pathogenesis such as $\mathrm{p} 65 \mathrm{NF}-\kappa \mathrm{B}$ interact with proteins containing bromodomains (67), and BrDi could suppress their acetylation in a more specific manner. For instance, NF-кB transcriptional activity is dependent upon its acetylation at lysine 310 (Lys310), and Lys310-acetylated p65 NF- $\mathrm{B}$ recruits the BET protein $\mathrm{BRD} 4$ in complex with positive transcription elongation factor $\mathrm{b}(\mathrm{p}-\mathrm{TEFb})$ and RNA polymerase II that together form a productive transcriptional machinery complex (68). We reported that a BET-specific BrDi MS417 suppresses TNF- $\alpha$ induced acetylation of $\mathrm{p} 65 \mathrm{NF}-\kappa \mathrm{B}$ and the expression of NF- $\kappa \mathrm{B}$ target genes in kidney cells in vitro and attenuates proteinuria and glomerulosclerosis in a mouse model of HIV-associated nephropathy in vivo. MS417 also inhibited AGE-induced acetylation of $\mathrm{p} 65 \mathrm{NF}-\kappa \mathrm{B}$ in podocytes in vitro and mitigated proteinuria in diabetic $d b / d b$ mice. Therefore, MS417 or other BrDi might be another class of potential drug candidates to treat DKD patients.

In summary, SIRT1 has significant renoprotective effects against podocyte injury in DKD (Figure 1), and SIRT1 agonists and bromodomain inhibitors are promising candidates as therapeutic approach in treatment of DKD patients.

\section{Clinical Perspectives}

Since a large amount of evidence suggest that Sirt1 is a key molecule involving in the pathogenesis of DKD and the expression of Sirt1 is suppressed in human diabetic kidney, enhancing the SIRT1-induced transcription factor deacetylation via SIRT1 agonists or bromodomain inhibitors may serve as potential therapies for human DKD.

\section{AUTHOR CONTRIBUTIONS}

All authors listed have made a substantial, direct and intellectual contribution to the work, and approved it for publication.

\section{ACKNOWLEDGMENTS}

YZ is supported by National Natural Science Foundation of China (2015-81573768), Shanghai Shuguang Scholar (20166SG37), Shanghai Three Years' Pilot Project (ZY3-CCCX-2-1002, ZY3-CCCX-3-2001), and Award from Chen Yiping's National Research Studio for Famous Chinese Medicine Practitioners; KL is supported by $\mathrm{NIH} 1 \mathrm{R} 01 \mathrm{DK} 117913$; and $\mathrm{JH}$ is supported by NIH 1R01DK078897, NIH 1R01DK088541.

\section{REFERENCES}

1. Moynihan KA, Grimm AA, Plueger MM, Bernal-Mizrachi E, Ford E, CrasMeneur C, et al. Increased dosage of mammalian Sir2 in pancreatic beta cells enhances glucose-stimulated insulin secretion in mice. Cell Metab. (2005) 2:105-17. doi: 10.1016/j.cmet.2005.07.001

2. Rodgers JT, Lerin C, Haas W, Gygi SP, Spiegelman BM, Puigserver P. Nutrient control of glucose homeostasis through a complex of PGC-1alpha and SIRT1. Nature (2005) 434:113-8. doi: 10.1038/nature03354

3. Salminen A, Kaarniranta K. SIRT1: regulation of longevity via autophagy. Cell Signal (2009) 21:1356-60. doi: 10.1016/j.cellsig.2009.02.014

4. Scarpulla RC. Metabolic control of mitochondrial biogenesis through the PGC-1 family regulatory network. Biochim Biophys Acta (2011) 1813:1269-78. doi: 10.1016/j.bbamcr.2010.09.019

5. Luo J, Nikolaev AY, Imai S, Chen D, Su F, Shiloh A, et al. Negative control of p53 by Sir2alpha promotes cell survival under stress. Cell (2001) 107:137-48. doi: 10.1016/S0092-8674(01) 00524-4

6. Hasegawa K, Wakino S, Yoshioka K, Tatematsu S, Hara Y, Minakuchi H, et al. Kidney-specific overexpression of Sirt1 protects against acute kidney injury by retaining peroxisome function. J Biol Chem. (2010) 285:13045-56. doi: 10.1074/jbc.M109.067728 
7. He W, Wang Y, Zhang MZ, You L, Davis LS, Fan H, et al. Sirt1 activation protects the mouse renal medulla from oxidative injury. J Clin Invest. (2010) 120:1056-68. doi: 10.1172/JCI41563

8. Kume S, Uzu T, Horiike K, Chin-Kanasaki M, Isshiki K, Araki S, et al. Calorie restriction enhances cell adaptation to hypoxia through Sirt1dependent mitochondrial autophagy in mouse aged kidney. J Clin Invest. (2010) 120:1043-55. doi: 10.1172/JCI41376

9. Nakagawa T, Guarente L. Sirtuins at a glance. J Cell Sci. (2011) 124:833-8. doi: $10.1242 /$ jcs.081067

10. Vaziri H, Dessain SK, Ng Eaton E, Imai SI, Frye RA, Pandita TK, et al. hSIR2(SIRT1) functions as an NAD-dependent p53 deacetylase. Cell (2001) 107:149-59. doi: 10.1016/S0092-8674(01)00527-X

11. Jang SY, Kim SY, Bae YS. p53 deacetylation by SIRT1 decreases during protein kinase CKII downregulation-mediated cellular senescence. FEBS Lett. (2011) 585:3360-6. doi: 10.1016/j.febslet.2011.09.027

12. Milner J, Allison SJ. SIRT1, p53 and mitotic chromosomes. Cell Cycle (2011) 10:3049. doi: 10.4161/cc.10.18.16994

13. Shah ZH, Ahmed SU, Ford JR, Allison SJ, Knight JR, Milner J. A deacetylasedeficient SIRT1 variant opposes full-length SIRT1 in regulating tumor suppressor p53 and governs expression of cancer-related genes. Mol Cell Biol. (2012) 32:704-16. doi: 10.1128/MCB.06448-11

14. Brunet A, Sweeney LB, Sturgill JF, Chua KF, Greer PL, Lin Y, et al. Stressdependent regulation of FOXO transcription factors by the SIRT1 deacetylase. Science (2004) 303:2011-5. doi: 10.1126/science.1094637

15. Motta MC, Divecha N, Lemieux M, Kamel C, Chen D, Gu W, et al. Mammalian SIRT1 represses forkhead transcription factors. Cell (2004) 116:551-63. doi: 10.1016/S0092-8674(04)00126-6

16. Chuang PY, Yu Q, Fang W, Uribarri J, He JC. Advanced glycation endproducts induce podocyte apoptosis by activation of the FOXO4 transcription factor. Kidney Int. (2007) 72:965-76. doi: 10.1038/sj.ki.5002456

17. Chuang PY, Dai Y, Liu R, He H, Kretzler M, Jim B, et al. Alteration of forkhead box $\mathrm{O}$ (foxo4) acetylation mediates apoptosis of podocytes in diabetes mellitus. PLoS ONE (2011) 6:e23566. doi: 10.1371/journal.pone.0023566

18. Bernier M, Paul RK, Martin-Montalvo A, Scheibye-Knudsen M, Song $\mathrm{S}$, He HJ, et al. Negative regulation of STAT3 protein-mediated cellular respiration by SIRT1 protein. J Biol Chem. (2011) 286:19270-9. doi: 10.1074/jbc.M110.200311

19. Nie Y, Erion DM, Yuan Z, Dietrich M, Shulman GI, Horvath TL, et al. STAT3 inhibition of gluconeogenesis is downregulated by SirT1. Nat Cell Biol. (2009) 11:492-500. doi: 10.1038/ncb1857

20. Sestito R, Madonna S, Scarponi C, Cianfarani F, Failla CM, Cavani A, et al. STAT3-dependent effects of IL-22 in human keratinocytes are counterregulated by sirtuin 1 through a direct inhibition of STAT3 acetylation. FASEB J. (2011) 25:916-27. doi: 10.1096/fj.10-172288

21. Schenk S, Mccurdy CE, Philp A, Chen MZ, Holliday MJ, Bandyopadhyay GK, et al. Sirtl enhances skeletal muscle insulin sensitivity in mice during caloric restriction. J Clin Invest. (2011) 121:4281-8. doi: 10.1172/JCI58554

22. Chen L, Fischle W, Verdin E, Greene WC. Duration of nuclear NFkappaB action regulated by reversible acetylation. Science (2001) 293:1653-7. doi: $10.1126 /$ science. 1062374

23. Greene WC, Chen LF. Regulation of NF-kappaB action by reversible acetylation. Novartis Found Symp. (2004) 259:208-17; discussion 218-225. doi: 10.1002/0470862637.ch15

24. Yang XD, Tajkhorshid E, Chen LF. Functional interplay between acetylation and methylation of the RelA subunit of NF-kappaB. Mol Cell Biol. (2010) 30:2170-80. doi: 10.1128/MCB.01343-09

25. Geng H, Harvey CT, Pittsenbarger J, Liu Q, Beer TM, Xue C, et al. HDAC4 protein regulates HIFlalpha protein lysine acetylation and cancer cell response to hypoxia. J Biol Chem. (2011) 286:38095-102. doi: 10.1074/jbc.M111.257055

26. Lim JH, Lee YM, Chun YS, Chen J, Kim JE, Park JW. Sirtuin 1 modulates cellular responses to hypoxia by deacetylating hypoxia-inducible factor 1alpha. Mol Cell (2010) 38:864-78. doi: 10.1016/j.molcel.2010.05.023

27. Chen R, Dioum EM, Hogg RT, Gerard RD, Garcia JA. Hypoxia increases sirtuin 1 expression in a hypoxia-inducible factor-dependent manner. J Biol Chem. (2011) 286:13869-78. doi: 10.1074/jbc.M110.175414

28. Usrds I. Annual Data Report: Atlas of End-Stage-Renal-Disease in the United States. (2011).
29. Kitada M, Takeda A, Nagai T, Ito H, Kanasaki K, Koya D. Dietary restriction ameliorates diabetic nephropathy through anti-inflammatory effects and regulation of the autophagy via restoration of Sirt1 in diabetic Wistar fatty (fa/fa) rats: a model of type 2 diabetes. Exp Diabetes Res. (2011b) 2011:908185. doi: $10.1155 / 2011 / 908185$

30. Kitada M, Kume S, Imaizumi N, Koya D. Resveratrol improves oxidative stress and protects against diabetic nephropathy through normalization of $\mathrm{Mn}$ SOD dysfunction in AMPK/SIRT1-independent pathway. Diabetes (2011a) 60:634-43. doi: 10.2337/db10-0386

31. Kim MY, Lim JH, Youn HH, Hong YA, Yang KS, Park HS, et al. Resveratrol prevents renal lipotoxicity and inhibits mesangial cell glucotoxicity in a manner dependent on the AMPK-SIRT1-PGC1alpha axis in $\mathrm{db} / \mathrm{db}$ mice. Diabetologia (2013) 56:204-17. doi: 10.1007/s00125-012-2747-2

32. Hasegawa K, Wakino S, Simic P, Sakamaki Y, Minakuchi H, Fujimura K, et al. Renal tubular Sirt1 attenuates diabetic albuminuria by epigenetically suppressing Claudin-1 overexpression in podocytes. Nat Med. (2013) 19:1496-504. doi: 10.1038/nm.3363

33. Liu R, Zhong Y, Li X, Chen H, Jim B, Zhou MM, et al. Role of transcription factor acetylation in diabetic kidney disease. Diabetes (2014) 63:2440-53. doi: $10.2337 / \mathrm{db} 13-1810$

34. Chuang PY, Xu J, Dai Y, Jia F, Mallipattu SK, Yacoub R, et al. In vivo RNA interference models of inducible and reversible Sirt1 knockdown in kidney cells. Am J Pathol. (2014) 184:1940-56. doi: 10.1016/j.ajpath.2014.03.016

35. Lo CS, Shi Y, Chenier I, Ghosh A, Wu CH, Cailhier JF, et al. Heterogeneous nuclear ribonucleoprotein $\mathrm{f}$ stimulates sirtuin-1 gene expression and attenuates nephropathy progression in diabetic mice. Diabetes (2017) 66:1964-78. doi: 10.2337/db16-1588

36. Hou S, Zhang T, Li Y, Guo F, Jin X. Glycyrrhizic acid prevents diabetic nephropathy by activating AMPK/SIRT1/PGC-1alpha signaling in $\mathrm{db} / \mathrm{db}$ mice. J Diabetes Res. (2017) 2017:2865912. doi: 10.1155/2017/2865912

37. Li X, Cai W, Lee K, Liu B, Deng Y, Chen Y, et al. Puerarin attenuates diabetic kidney injury through the suppression of NOX4 expression in podocytes. Sci Rep. (2017) 7:14603. doi: 10.1038/s41598-017-17925-7

38. Du YG, Zhang KN, Gao ZL, Dai F, Wu XX, Chai KF. Tangshen formula improves inflammation in renal tissue of diabetic nephropathy through SIRT1/NF-kappaB pathway. Exp Ther Med. (2018) 15:2156-64. doi: 10.3892/etm.2017.5621

39. Hong Q, Zhang L, Das B, Li Z, Liu B, Cai G, et al. Increased podocyte Sirtuin1 function attenuates diabetic kidney injury. Kidney Int. (2018) 93:1330-43 doi: 10.1016/j.kint.2017.12.008

40. Maeda S, Koya D, Araki SI, Babazono T, Umezono T, Toyoda M, et al. Association between single nucleotide polymorphisms within genes encoding sirtuin families and diabetic nephropathy in Japanese subjects with type 2 diabetes. Clin Exp Nephrol. (2011) 15:381-90. doi: 10.1007/s10157-011-0418-0

41. Kume S, Thomas MC, Koya D. Nutrient sensing, autophagy, and diabetic nephropathy. Diabetes (2012) 61:23-9. doi: 10.2337/db11-0555

42. Kitada M, Ogura Y, Monno I, Koya D. Regulating autophagy as a therapeutic target for diabetic nephropathy. Curr Diab Rep. (2017) 17:53. doi: 10.1007/s11892-017-0879-y

43. Wen D, Huang X, Zhang M, Zhang L, Chen J, Gu Y, et al. Resveratrol attenuates diabetic nephropathy via modulating angiogenesis. PLoS ONE (2013) 8:e82336. doi: 10.1371/journal.pone.0082336

44. Fan H, Yang HC, You L, Wang YY, He WJ, Hao CM. The histone deacetylase, SIRT1, contributes to the resistance of young mice to ischemia/reperfusion-induced acute kidney injury. Kidney Int. (2013) 83:40413. doi: 10.1038/ki.2012.394

45. Nakatani Y, Inagi R. Epigenetic regulation through SIRT1 in podocytes. Curr Hypertens Rev. (2016) 12:89-94. doi: 10.2174/1573402112666160302102515

46. Hao CM, Haase VH. Sirtuins and their relevance to the kidney. J Am Soc Nephrol. (2010) 21:1620-7. doi: 10.1681/ASN.2010010046

47. Morigi M, Perico L, Benigni A. Sirtuins in renal health and disease. J Am Soc Nephrol. (2018) 29:1799-809. doi: 10.1681/ASN.2017111218

48. Berthier CC, Zhang H, Schin M, Henger A, Nelson RG, Yee B, et al. Enhanced expression of Janus kinase-signal transducer and activator of transcription pathway members in human diabetic nephropathy. Diabetes (2009) 58:46977. doi: $10.2337 / \mathrm{db} 08-1328$

49. Schmid H, Boucherot A, Yasuda Y, Henger A, Brunner B, Eichinger F, et al. Modular activation of nuclear factor-kappaB transcriptional 
programs in human diabetic nephropathy. Diabetes (2006) 55:2993-3003. doi: $10.2337 /$ db06-0477

50. Niranjan T, Bielesz B, Gruenwald A, Ponda MP, Kopp JB, Thomas DB, et al. The Notch pathway in podocytes plays a role in the development of glomerular disease. Nat Med. (2008) 14:290-8. doi: 10.1038/nm1731

51. Tikoo K, Tripathi DN, Kabra DG, Sharma V, Gaikwad AB. Intermittent fasting prevents the progression of type I diabetic nephropathy in rats and changes the expression of Sir2 and p53. FEBS Lett. (2007) 581:1071-8. doi: 10.1016/j.febslet.2007.02.006

52. Brezniceanu ML, Liu F, Wei CC, Tran S, Sachetelli S, Zhang SL, et al. Catalase overexpression attenuates angiotensinogen expression and apoptosis in diabetic mice. Kidney Int. (2007) 71:912-23. doi: 10.1038/sj.ki. 5002188

53. Tran D, Bergholz J, Zhang H, He H, Wang Y, Zhang Y, et al. Insulin-like growth factor-1 regulates the SIRT1-p53 pathway in cellular senescence. Aging Cell (2014) 13:669-78. doi: 10.1111/acel.12219

54. Xiong S, Salazar G, Patrushev N, Ma M, Forouzandeh F, Hilenski L, et al. Peroxisome proliferator-activated receptor gamma coactivatorlalpha is a central negative regulator of vascular senescence. Arterioscler Thromb Vasc Biol. (2013) 33:988-98. doi: 10.1161/ATVBAHA.112. 301019

55. Imai S, Guarente L. NAD+ and sirtuins in aging and disease. Trends Cell Biol. (2014) 24:464-71. doi: 10.1016/j.tcb.2014.04.002

56. Yuan Y, Huang S, Wang W, Wang Y, Zhang P, Zhu C, et al. Activation of peroxisome proliferator-activated receptor-gamma coactivator 1alpha ameliorates mitochondrial dysfunction and protects podocytes from aldosterone-induced injury. Kidney Int. (2012) 82:771-89. doi: $10.1038 / \mathrm{ki} .2012 .188$

57. Lv J, Jiang S, Yang Z, Hu W, Wang Z, Li T, et al. PGC-1alpha sparks the fire of neuroprotection against neurodegenerative disorders. Ageing Res Rev. (2018) 44:8-21. doi: 10.1016/j.arr.2018.03.004

58. Chen J, Xavier S, Moskowitz-Kassai E, Chen R, Lu CY, Sanduski K, et al. Cathepsin cleavage of sirtuin 1 in endothelial progenitor cells mediates stress-induced premature senescence. Am J Pathol. (2012) 180:973-83. doi: 10.1016/j.ajpath.2011.11.033

59. Portilla D. Apoptosis, fibrosis and senescence. Nephron Clin Pract. (2014) 127:65-9. doi: 10.1159/000363717

60. Clements ME, Chaber CJ, Ledbetter SR, Zuk A. Increased cellular senescence and vascular rarefaction exacerbate the progression of kidney fibrosis in aged mice following transient ischemic injury. PLoS ONE (2013) 8:e70464. doi: 10.1371/journal.pone.0070464

61. Chuang PY, Cai W, Li X, Fang L, Xu J, Yacoub R, et al. Reduction in podocyte SIRT1 accelerates kidney injury in aging mice. Am J Physiol Renal Physiol. (2017) 313:F621-8. doi: 10.1152/ajprenal.00255.2017

62. Li J, Qu X, Ricardo SD, Bertram JF, Nikolic-Paterson DJ. Resveratrol inhibits renal fibrosis in the obstructed kidney: potential role in deacetylation of Smad3. Am J Pathol. (2010) 177:1065-71. doi: 10.2353/ajpath.2010.090923

63. Huang KP, Chen C, Hao J, Huang JY, Liu PQ, Huang HQ. AGEs-RAGE system down-regulates Sirt1 through the ubiquitin-proteasome pathway to promote FN and TGF-betal expression in male rat glomerular mesangial cells. Endocrinology (2015) 156:268-79. doi: 10.1210/en.2014-1381

64. Beher D, Wu J, Cumine S, Kim KW, Lu SC, Atangan L, et al. Resveratrol is not a direct activator of SIRT1 enzyme activity. Chem Biol Drug Des. (2009) 74:619-24. doi: 10.1111/j.1747-0285.2009.00901.x

65. Pacholec M, Bleasdale JE, Chrunyk B, Cunningham D, Flynn D, Garofalo RS, et al. SRT1720, SRT2183, SRT1460, and resveratrol are not direct activators of SIRT1. J Biol Chem. (2010) 285:8340-51. doi: 10.1074/jbc.M109.088682

66. Rogacka D, Audzeyenka I, Rychlowski M, Rachubik P, Szrejder M, Angielski $\mathrm{S}$, et al. Metformin overcomes high glucose-induced insulin resistance of podocytes by pleiotropic effects on SIRT1 and AMPK. Biochim Biophys Acta (2018) 1864:115-25. doi: 10.1016/j.bbadis.2017.10.014

67. Sanchez R, Meslamani J, Zhou MM. The bromodomain: from epigenome reader to druggable target. Biochim Biophys Acta (2014) 1839:676-85. doi: 10.1016/j.bbagrm.2014.03.011

68. Huang B, Yang XD, Zhou MM, Ozato K, Chen LF. Brd4 coactivates transcriptional activation of NF-kappaB via specific binding to acetylated RelA. Mol Cell Biol. (2009) 29:1375-87. doi: 10.1128/MCB.01365-08

Conflict of Interest Statement: The authors declare that the research was conducted in the absence of any commercial or financial relationships that could be construed as a potential conflict of interest.

Copyright (c) 2018 Zhong, Lee and He. This is an open-access article distributed under the terms of the Creative Commons Attribution License (CC BY). The use, distribution or reproduction in other forums is permitted, provided the original author(s) and the copyright owner(s) are credited and that the original publication in this journal is cited, in accordance with accepted academic practice. No use, distribution or reproduction is permitted which does not comply with these terms. 